\title{
Update on medicines for smoking cessation
}

\section{Mike McDonough \\ Head of Addiction Medicine Western Health \\ Melbourne}

\section{Key words}

bupropion, nicotine,

smoking cessation,

varenicline

Aust Prescr 2015;38:106-11

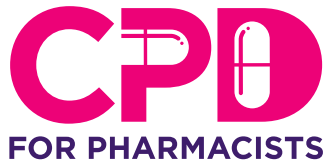

This article has a continuing professional development activity for pharmacists available at

www.australianprescriber.com/ continuing-professionaldevelopment

\section{SUMMARY}

Persistent cigarette smokers usually have a nicotine addiction. This addiction has a chronic relapsing and sometimes remitting course and may persist lifelong.

Remission can be facilitated by the use of medication as part of a comprehensive management strategy tailored to the individual patient.

Nicotine replacement therapy is a first-line drug treatment. It is available in many formulations.

Varenicline is also a first-line drug treatment. It should be started before the patient stops smoking.

Bupropion is a second-line therapy. It may be associated with an increased risk of seizures and drug interactions.

While there is some evidence that electronic cigarettes might facilitate smoking cessation, quit rates are not yet comparable with those of the drugs approved on the Pharmaceutical Benefits Scheme.

\section{Introduction}

Most tobacco smokers are addicted to nicotine.

This addiction is a chronic disease state that is prone to relapses and remissions.' However nicotine addiction is declining in Australia, indicating that for some smokers remission after quitting may be long lasting. In 2001, $22.4 \%$ of the population aged 18 or over smoked, while by 2011-12 this rate had reduced to $16.4 \% .^{2}$

Following the decline in smoking prevalence in Australia, the profile of smokers has changed. A

\section{From the Editor}

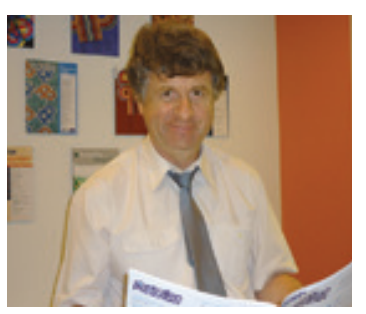

Tobacco, alcohol and diet contribute to several of the conditions reviewed in this issue of Australian Prescriber. Yong Wee, Kylie Burns and Nicholas Bett say that stopping smoking is a key part of the management of chronic stable angina and Mike McDonough explains how drugs can assist in smoking cessation.

Ela Hyland, Siobhan Connolly, Jade Fox and John Harvey advise on the management of minor burns and when patients should be sent to a specialist unit.

Obesity is the most important modifiable risk factor for osteoarthritis. Shirley Yu and David Hunter therefore recommend weight loss in the management of osteoarthritis.

Alcohol can cause pancreatitis, but there are many other possible causes. Chamara Basnayake and Dilip Ratnam outline how blood tests can help in the diagnosis of pancreatitis.

Obsessive compulsive disorder is one of the top 10 most disabling medical conditions. Vlasios Brakoulias reviews effective treatments for obsessive compulsive disorder. higher proportion now have more severe forms of nicotine addiction and comorbidity. ${ }^{3-5}$ Nonetheless, most smokers eventually consider quitting, so few smokers are completely resistant to interventions to stop smoking. Commonly, people who recover from addiction appear to learn how to manage lapses and relapses, largely from their experience of multiple cycles of lapse ('slip up') and relapse (reinstatement of dependence). A number of excellent recent reviews on smoking cessation are available. ${ }^{4-11}$

There is a lot of evidence regarding the efficacy of the drugs used in smoking cessation. ${ }^{6-10}$ There is also emerging evidence about tailoring interventions to individuals in a personalised medicine approach., 5,11,12 These drugs are most effective when used in conjunction with behavioural therapies and support (Box 1). Cognitive and behavioural interventions, such as motivational interviewing and relapse prevention, are an essential adjunct to the efficacy of these drugs. ${ }^{6-10}$ Smoking cessation is more likely to succeed when the smoker is motivated to quit, hence skill in motivational interviewing is additionally helpful for the practitioner. Recent evidence suggests some smoking cessation programs that also provide financial incentives for participants can be highly effective. ${ }^{13}$

It is essential that both doctor and patient persevere in managing nicotine addiction regardless of apparently entrenched negative beliefs or the number of previous attempts to quit. The management focus is to help prevent relapse and to continue being supportive when relapse occurs, providing encouragement for further attempts to quit in the future. Common risks for lapse or relapse include 
stressful circumstances, consuming alcohol and being with friends or family who smoke.

\section{Indications for drug treatment}

Smokers who are not physiologically dependent on nicotine and are ready to quit are more likely to respond to behavioural interventions than dependent patients. Most current smokers are likely to be significantly nicotine dependent (Box 2), so it is appropriate to consider drug therapy to help them quit.

There are three approved drug therapies in Australia varenicline, bupropion and nicotine replacement therapy. They are available on the Pharmaceutical Benefits Scheme (PBS), as long as they are part of a comprehensive treatment plan for smoking cessation. A Cochrane review has compared the efficacy of drugs that support quitting for six months or longer (Table). ${ }^{6}$ Nortriptyline and clonidine are sometimes prescribed 'off-label' for smoking cessation, however their efficacy is not as good as that of the approved drugs. ${ }^{6}$

\section{Nicotine replacement therapy}

For most patients, nicotine replacement therapy should still be considered first line because of its established evidence base. ${ }^{14}$ Multiple formulations are available - gum, lozenges, oral strips, spray, inhaler, patches (16- or 24-hour release) and sublingual tablets. All have comparable efficacy. These different formulations allow for better tailoring to individual requirements including the use of combinations if required. For example, a patient may be prescribed a transdermal nicotine patch and additionally use a nicotine inhaler to supplement blood nicotine concentrations at times of particular craving or risk of relapse. Evidence suggests that combinations of nicotine replacement therapy may be more effective than using a single formulation. ${ }^{6}$

Transdermal patches are a common form of nicotine replacement therapy. It is recommended to start with a higher dose formulation (e.g. $21 \mathrm{mg}$ ) and to consider the 16-hour patch for patients who do not usually smoke during the night, to avoid sleep disturbance. Both patch durations are equally efficacious. It is important to provide an adequate dose of nicotine to reduce withdrawal symptoms and risk of relapse, then continue treatment for the appropriate duration (e.g. 12 weeks). Generally, heavier smokers (e.g. more than a packet/day) will require bigger replacement doses of nicotine. Sometimes, two transdermal patches may be required. Advise heavily dependent patients about self-titration of the nicotine dose using additional short-acting formulations like gum, spray or inhaler.

\section{Box 1 Resources to support smoking cessation}

\author{
QUIT-line \\ Counselling for consumers \\ www.quitnow.gov.au or phone 137848 (13 QUIT) \\ Mental health information \\ www.quitnow.gov.au - Go to the tab 'I want info on' and then 'Mental illness and quitting' \\ (health professionals and patient information sheets). \\ www.sane.org - Go to the tab 'Information' select 'Factsheets and podcasts', under \\ 'Mind \& body' select 'Smoking and mental illness' (patient information sheet). \\ Pregnancy-related information \\ www.quitnow.gov.au/internet/quitnow/publishing.nsf/Content/pregnancy-and-quitting \\ http://nnswlhd.health.nsw.gov.au/health-promotion/closing-the-gap/smokefree \\ This site provides access to the 'Quit for New Life' program which especially targets \\ Aboriginal mothers.
}

\section{Aboriginal and Torres Strait Islander information \\ http://nnswlhd.health.nsw.gov.au/health-promotion/closing-the-gap/smokefree www.qld.gov.au/atsi/health-staying-active/quit-smoking}

\section{NPS MedicineWise}

Stop smoking - what works for your patients? www.nps.org.au/publications/health-professional/health-news-evidence/2013/ stop-smoking-what-works

Australian Association of Smoking Cessation Professionals http://aascp.org.au

Royal Australian College of General Practitioners

Supporting smoking cessation: a guide for health professionals www.racgp.org.au/guidelines/smoking-cessation

Royal Australasian College of Physicians

Smoking cessation training module

https://elearning.racp.edu.au - Go to the tab 'Addiction medicine'.

\section{Cochrane Tobacco Addiction Group}

http://tobacco.cochrane.org/evidence

National Cannabis Prevention and Information Centre

www.ncpic.org.au

\section{Box 2 Features of severe nicotine} dependence

Smoking in first five minutes after waking

Smoking despite illness, such as respiratory tract infections

Waking during the night to smoke

Smoking to reduce withdrawal symptoms

Smoking more than a packet of cigarettes a day

The more features present, the more severe the dependence 
Table Comparative efficacy of drugs for smoking cessation ${ }^{6}$

\begin{tabular}{ll}
\hline Comparison & Odds ratio * \\
\hline NRT vs placebo & $1.84(1.71-1.99)$ \\
Combination NRT vs placebo & $2.04(1.25-2.38)$ \\
Bupropion vs placebo & $1.82(1.6-2.06)$ \\
Varenicline vs placebo & $2.88(2.4-3.47)$ \\
Combination NRT vs monotherapy NRT & $1.34(1.0-1.8)$ \\
Bupropion vs NRT & $0.99(0.86-1.13)$ \\
Varenicline vs NRT & $1.57(1.29-1.91)$ \\
Varenicline vs combination NRT & $1.06(0.75-1.48)$ \\
Varenicline vs bupropion & $1.59(1.29-1.96)$
\end{tabular}

NRT nicotine replacement therapy

* odds ratio (with 95\% confidence interval) calculated on quit rates for six months or longer
It is therefore recommended as an equal first-line drug for smoking cessation.

Varenicline acts as a partial agonist at central nicotinic receptors, which are important in mediating the reinforcement associated with tobacco smoking. ${ }^{5,6}$ During treatment, drug binding partially activates these receptors thereby reducing withdrawal symptoms and cravings. If the patient lapses and smokes, varenicline reduces the access of nicotine to the receptors. By limiting nicotine binding, its rewarding effect is reduced.

It is recommended that varenicline is started a week or two before the patient stops smoking. This is because a continuous period of dosing is required before sufficient receptors are occupied and optimal drug efficacy is achieved. The dose is gradually increased and treatment continues for 12 weeks. If the patient is not initially successful in quitting within a six-month period, the PBS subsidises an additional 12 weeks supply of varenicline (up to two authority prescriptions per 12 months). ${ }^{15}$ Varenicline can be combined safely with nicotine replacement therapy and this may further improve abstinence rates at six months. ${ }^{16}$ Varenicline is principally eliminated by the kidney so reduced doses (or alternative treatments) are recommended for patients with renal impairment. When varenicline was first marketed there were concerns about an apparent increased incidence of neuropsychiatric and cardiovascular adverse effects. After several years of experience with varenicline, these concerns do not appear to have been substantiated. 6,17,18 Common adverse effects include nausea, headache and insomnia.

\section{Bupropion}

Bupropion was originally developed as an antidepressant, but its mode of action in smoking cessation is uncertain. It has equivalent efficacy to nicotine replacement monotherapy but less efficacy than varenicline and is therefore considered a second-line option.

Bupropion is considered when other drugs have been ineffective or contraindicated. Although bupropion can be used in conjunction with nicotine replacement therapy, this combination appears not to offer improved efficacy. ${ }^{19}$

Like varenicline, bupropion is started before the patient stops smoking to allow sufficient time for the drug to mediate its therapeutic effects. A common strategy is for the patient to set a quit date for the second week of therapy.

Bupropion is contraindicated in patients with a history of seizures. Common adverse effects include difficulty concentrating, insomnia and nightmares. Bupropion undergoes significant hepatic cytochrome 
P450 2B6 metabolism to an active metabolite (hydroxybupropion) which is later excreted renally. Dose reduction is necessary in patients with hepatic or renal disease. There are potential interactions with other drugs metabolised by this system including selective serotonin reuptake inhibitors and St John's wort. ${ }^{20}$

\section{Personalising drug treatment}

Among the more common reasons for a poor response to drug treatment are non-adherence, adverse effects, and inadequate dosing particularly with nicotine replacement therapy. Personalising treatment may prevent some of these problems. The choice of drug depends on patient factors and their environment.

\section{Patient factors}

Consider any individual preferences, past experiences or medical conditions. For example, nicotine gum usually does not suit patients with dentures, and in Sjogren's syndrome nicotine lozenges or strips are less likely to be effective due to decreased saliva production. Aphthous ulceration is a recognised adverse consequence related to smoking cessation and not an adverse effect of drugs used to assist quitting. ${ }^{21}$

The patient might have a generalised dermatological condition that makes transdermal patches less appropriate. Other individual factors to consider include chronic renal or hepatic disease, diabetes (glycaemic control may be unstable during smoking cessation), unstable angina, pregnancy and lactation.

Many smokers have comorbid mental health problems such as anxiety or mood disorder. Identifying these problems can help in determining the need for specific treatments to further facilitate the smoking cessation attempt - for example, engaging the patient in a mental health treatment plan involving a psychologist who can provide assistance with the mental health problem and support smoking cessation. Quitting smoking has been shown to improve the mental health of patients with psychiatric comorbidity and does not exacerbate their symptoms. ${ }^{22-27}$

Patients with significant depressive symptoms are known to be less likely to respond to smoking cessation interventions. Some may need antidepressant treatment before they will engage in smoking cessation. Although bupropion has antidepressant activity, it has no more efficacy in depressed smokers than other drugs for smoking cessation. ${ }^{24}$ Encouragingly, evidence supports smoking cessation interventions even in groups previously thought to be resistant, such as patients with chronic psychotic illness, the homeless, the socially disadvantaged and people with other forms of substance abuse..$^{28,29}$ Caution is needed in patients taking antipsychotic drugs as smoking cessation can lead to rising blood concentrations of drugs such as clozapine and olanzapine. ${ }^{30}$

Women planning pregnancy should be encouraged to give up smoking. Preconception counselling and antenatal visits are opportunities to reinforce this advice. Patient education and behavioural interventions are recommended as first-line interventions. There are special smoking cessation resources for pregnant women (Box 1). If drugs are considered, neither varenicline nor bupropion is recommended. Although evidence supporting the use of nicotine replacement therapy in pregnancy is limited, it is likely to be much safer than smoking. ${ }^{31-33}$

Adolescent smokers are less likely to be severely nicotine dependent. A small group may be dependent and there is some evidence supporting the use of nicotine replacement therapy, notably patches and gum. ${ }^{34}$

\section{Environment}

Assessing the patient's environment involves identifying the factors that positively or negatively affect adherence to the smoking cessation plan. ${ }^{35}$ For example, the patient may have a partner who continues to smoke at home, or friends or a workplace that exposes them to risks for lapse or relapse. Patients should be helped to develop strategies to better negotiate these situations. Other supports include the QUIT-line providing telephone followup, text messaging to enhance adherence ${ }^{35,36}$ and engaging mindfulness therapy. ${ }^{37}$ Some patients may need specialist referral, for example contacting the Australian Association of Smoking Cessation Professionals or an addiction medicine specialist.

\section{Electronic cigarettes}

Electronic cigarettes (e-cigarettes) are typically handheld, battery-operated devices that deliver vaporised liquid ('e-juice') containing flavourings and sometimes nicotine. The vapour is inhaled by the user in a fashion similar to smoking but without inhaling tobacco tar and carbon monoxide. The process of inhaling these vapours is referred to as 'vaping'. In Australia nicotinedelivering cartridges are not available over the counter and require individual importation licensing (for personal use only), a medical prescription and are subject to various state legislative sanctions. Some patients source nicotine e-juice over the internet from the USA, Canada and China.

Some recent evidence including a Cochrane review suggests these devices may help some people quit smoking. ${ }^{38,39}$ However they have not been shown to be more effective than current smoking cessation drugs. Further, there are concerns about safety (e.g. constituents of the vapour may be toxic 


\section{SELF-TEST QUESTIONS}

True or false?

1. A 16-hour nicotine patch is less efficacious than a 24-hour nicotine patch.

2. Varenicline cannot be combined with nicotine replacement therapy. to the lung) and the marketing of e-cigarettes, especially towards young people and current nonsmokers. Some advertising suggests to smokers that they use e-cigarettes during times when they are unable to smoke cigarettes rather than as an aid to smoking cessation. ${ }^{40-43}$

Of concern is the evidence of increasing use of nicotinecontaining e-cigarettes by non-smoking adolescents and young adults. ${ }^{44}$ Further, some evidence suggests that nicotine may function as a gateway drug to future drug addiction by enhancing the brain's susceptibility to be rewarded by other addictive drugs. ${ }^{45}$

\section{Cannabis}

Most cannabis smokers also smoke tobacco. There is evidence suggesting that tobacco increases cannabis dependence ${ }^{46}$ and that cannabis use increases difficulty of tobacco cessation. ${ }^{47}$ Assisting smokers to quit tobacco may also assist with cannabis cessation and vice versa. A recent Cochrane review on cannabis dependence found few good studies and insufficient evidence for most treatments trialled. However, they and others suggest a few drugs that might warrant further investigation. ${ }^{48,49}$ The National Cannabis Prevention and Information Centre provides good resources and support for cannabis cessation (Box 1).

\section{Conclusion}

Current cigarette smokers are likely to be significantly nicotine dependent. To help them quit there are several options for drug therapy, and prescribers, like smokers themselves, need encouragement to persevere despite past unsuccessful attempts. These drugs have good efficacy particularly when used in conjunction with a comprehensive treatment plan. A focus on personalised interventions and relapse prevention is recommended. It is essential to provide support and there are many support services now available including specialist referral. $<$

Conflict of interest: none declared

\section{REFERENCES}

1. McLellan AT, Lewis DC, O’Brien CP, Kleber HD. Drug dependence, a chronic medical illness: implications for treatment insurance, and outcomes evaluation. JAMA 2000;284:1689-95.

2. Australian Bureau of Statistics 4364.0.55.003 - Australian Health Survey: Updated Results, 2011-2012. Canberra: ABS; 2013 June.

www.abs.gov.au/ausstats/abs@.nsf/Lookup/4364.0.55.003 Chapter12011-2012 [cited 2015 Jul 1]

3. Docherty G, McNeill A, Gartner C, Szatkowski L. Did hardening occur among smokers in England from 2000 to 2010? Addiction 2014:109:147-54

4. Benowitz NL. Nicotine addiction. N Engl J Med 2010;362:2295-303.

5. Benowitz NL. Pharmacology of nicotine: addiction, smoking-induced disease, and therapeutics. Annu Rev Pharmacol Toxicol 2009;49:57-71.

6. Cahill K, Stevens S, Perera R, Lancaster T. Pharmacological interventions for smoking cessation: an overview and network meta-analysis. Cochrane Database Syst Rev 2013:CD009329.

7. Bauld L, Bell K, McCullough L, Richardson L, Greaves L. The effectiveness of NHS smoking cessation services: a systematic review. J Public Health (Oxf) 2010;32:71-82.

8. Kotz D, Brown J, West R. 'Real-world' effectiveness of smoking cessation treatments: a population study. Addiction 2014;109:491-9.

9. Hartmann-Boyce J, Stead LF, Cahill K, Lancaster T. Efficacy of interventions to combat tobacco addiction: Cochrane update of 2012 reviews. Addiction 2013;108:1711-21.

10. Fiore MC, Baker TB. Clinical practice. Treating smokers in the health care setting. N Engl J Med 2011;365:1222-31.

11. Zwar NA, Mendelsohn CP, Richmond RL. Tobacco smoking: options for helping smokers to quit. Aust Fam Physician 2014;43:348-54.

12. Mohsin M, Bauman AE. Socio-demographic factors associated with smoking and smoking cessation among 426,344 pregnant women in New South Wales, Australia. BMC Public Health 2005;5:138.

13. Halpern SD, French B, Small DS, Saulsgiver K, Harhay MO Audrain-McGovern J, et al. Randomized trial of four financial-incentive programs for smoking cessation. N Engl J Med 2015;372:2108-17.

14. Stead LF, Perera R, Bullen C, Mant D, Hartmann-Boyce J, Cahill K, et al. Nicotine replacement therapy for smoking cessation. Cochrane Database Syst Rev 2012:CD000146.
15. NPS MedicineWise. Varenicline (Champix) for smoking cessation - changed note to restriction. NPS Radar 2014 Dec 1.

www.nps.org.au/publications/health-professional/npsradar/2014/october-2014/brief-item-varenicline [cited 2015 Jul 1]

16. Koegelenberg CF, Noor F, Bateman ED, van Zyl-Smit RN, Bruning A, O'Brien JA, et al. Efficacy of varenicline combined with nicotine replacement therapy vs varenicline alone for smoking cessation: a randomized clinical trial. JAMA 2014;312:155-61.

17. Gibbons RD, Mann JJ. Varenicline, smoking cessation, and neuropsychiatric adverse events. Am J Psychiatry 2013;170:1460-7.

18. Chelladurai Y, Singh S. Varenicline and cardiovascular adverse events: a perspective review. Ther Adv Drug Saf 2014;5:167-72.

19. Stapleton J, West R, Hajek P, Wheeler J, Vangeli E, Abdi Z, et al. Randomized trial of nicotine replacement therapy (NRT), bupropion and NRT plus bupropion for smoking cessation: effectiveness in clinical practice. Addiction 2013;108:2193-201.

20. Fava M, Rush AJ, Thase ME, Clayton A, Stahl SM, Pradko JF, et al. 15 years of clinical experience with bupropion $\mathrm{HCl}$ : from bupropion to bupropion SR to bupropion $\mathrm{XL}$. Prim Care Companion J Clin Psychiatry 2005;7:106-13.

21. McRobbie H, Hajek P, Gillison F. The relationship between smoking cessation and mouth ulcers. Nicotine Tob Res 2004;6:655-9.

22. Heckman BW, Kovacs MA, Marquinez NS, Meltzer LR, Tsambarlis ME, Drobes DJ, et al. Influence of affective manipulations on cigarette craving: a meta-analysis. Addiction 2013;108:2068-78.

23. van der Meer RM, Willemsen MC, Smit F, Cuijpers P. Smoking cessation interventions for smokers with current or past depression. Cochrane Database Syst Rev 2013:CD006102.

24. Hughes JR, Stead LF, Lancaster T. Antidepressants for smoking cessation. Cochrane Database Syst Rev 2007:CD000031.

25. Taylor G, McNeill A, Girling A, Farley A, Lindson-Hawley N, Aveyard $P$. Change in mental health after smoking cessation: systematic review and meta-analysis. BMJ 2014;348:91151.

26. Prochaska JJ. Smoking and mental illness - breaking the link. N Engl J Med 2011;365:196-8.

27. Ashton M, Rigby A, Galletly C. Evaluation of a communitybased smoking cessation programme for people with severe mental illness. Tob Control 2015;24:275-80. 
28. Apollonio D, Philipps R, Bero L. Interventions for tobacco use cessation in people in treatment for or recovery from substance abuse. Cochrane Libr 2012;12:1-10.

29. Baggett TP, Lebrun-Harris LA, Rigotti NA. Homelessness, cigarette smoking and desire to quit: results from a US national study. Addiction 2013;108:2009-18.

30. Lucas C, Martin J. Smoking and drug interactions. Aust Prescr 2013;36:102-4

31. Coleman T, Chamberlain C, Davey MA, Cooper SE, Leonardi-Bee J. Pharmacological interventions for promoting smoking cessation during pregnancy. Cochrane Database Syst Rev 2012:CD010078.

32. Mendelsohn C, Gould GS, Oncken C. Management of smoking in pregnant women. Aust Fam Physician 2014;43:46-51.

33. Cressman AM, Pupco A, Kim E, Koren G, Bozzo P. Smoking cessation therapy during pregnancy. Can Fam Physician 2012;58:525-7.

34. Karpinski JP, Timpe EM, Lubsch L. Smoking cessation treatment for adolescents. J Pediatr Pharmacol Ther 2010;15:249-63.

35. Raupach T, Brown J, Herbec A, Brose L, West R A systematic review of studies assessing the association between adherence to smoking cessation medication and treatment success. Addiction 2014;109:35-43.

36. Abroms LC, Boal AL, Simmens SJ, Mendel JA, Windsor RA A randomized trial of Text2Quit: a text messaging program for smoking cessation. Am J Prev Med 2014;47:242-50.

37. Brewer JA, Mallik S, Babuscio TA, Nich C, Johnson HE, Deleone CM, et al. Mindfulness training for smoking cessation: results from a randomized controlled trial. Drug Alcohol Depend 2011;119:72-80.

38. McRobbie H, Bullen C, Hartmann-Boyce J, Hajek P. Electronic cigarettes for smoking cessation and reduction. Cochrane Database Syst Rev 2014:CD010216.
39. Bullen C, Howe C, Laugesen M, McRobbie H, Parag V, Williman J, et al. Electronic cigarettes for smoking cessation: a randomised controlled trial. Lancet 2013;382:1629-37.

40. Hajek P, Etter JF, Benowitz N, Eissenberg T, McRobbie H. Electronic cigarettes: review of use, content, safety, effects on smokers and potential for harm and benefit. Addiction 2014;109:1801-10.

41. Weaver M, Breland A, Spindle T, Eissenberg T. Electronic cigarettes: a review of safety and clinical issues. J Addict Med 2014;8:234-40.

42. Grana R, Benowitz N, Glantz SA. E-cigarettes: a scientific review. Circulation 2014;129:1972-86.

43. Grana R, Benowitz N, Glantz S. Background paper on e-cigarettes (electronic nicotine delivery systems). San Francisco: Center for Tobacco Control Research and Education, University of California, WHO Collaborating Center on Tobacco Control; 2013. http://arizonansconcernedaboutsmoking.com/201312ecig report.pdf [cited $2015 \mathrm{Jul} 1]$

44. Chapman S. The future of electronic cigarette growth depends on youth uptake. Med J Aust 2015;202:467-8.

45. Kandel ER, Kandel DB. Shattuck Lecture. A molecular basis for nicotine as a gateway drug. N Engl J Med 2014;371:932-43.

46. Ream GL, Benoit E, Johnson BD, Dunlap E. Smoking tobacco along with marijuana increases symptoms of cannabis dependence. Drug Alcohol Depend 2008;95:199-208.

47. Ford DE, Vu HT, Anthony JC. Marijuana use and cessation of tobacco smoking in adults from a community sample. Drug Alcohol Depend 2002;67:243-8.

48. Marshall K, Gowing L, Ali R, Le Foll B. Pharmacotherapies for cannabis dependence. Cochrane Database Syst Rev 2014:CD008940.

49. Weinstein AM, Gorelick DA. Pharmacological treatment of cannabis dependence. Curr Pharm Des 2011;17:1351-8.

\section{Letters to the Editor}

\section{Antiplatelet drugs and the smokers' paradox}

The review on the new antiplatelet drugs (Aust Prescr 2014;37:182-6) was very useful and timely. However, one important aspect not mentioned was the influence of smoking status on drug efficacy. Smokers have an enhanced response to clopidogrel - the so-called smokers paradox.

A recent meta-analysis concluded that the clinical benefit of clopidogrel in reducing cardiovascular events was seen primarily in smokers (25\% risk reduction compared to controls), with little benefit in non-smokers (8\% reduction). ${ }^{2}$

Prasugrel and ticagrelor were 47\% and 36\% more effective respectively than clopidogrel in smokers. However, in non-smokers the risk reduction was a modest $15 \%$ and $18 \%$ respectively compared with controls. ${ }^{2}$

It would be helpful if the authors could comment on the clinical significance of these findings and their implications for drug selection and dosing. For example, is clopidogrel a suitable choice for nonsmokers and should they receive larger doses to improve efficacy? Should prasugrel and ticagrelor replace clopidogrel in smokers who quit? Are smokers at higher risk of major bleeds from these antiplatelet drugs?

Colin Mendelsohn

Tobacco treatment specialist The Sydney Clinic Consulting Rooms Sydney

Colin Mendelsohn has received payments for consultancy, educational presentations, travel and related expenses from Pfizer Australia, GlaxoSmithKline and Johnson \& Johnson Pacific.

\section{REFERENCES}

1. Swiger KJ, Yousuf O, Bliden KP, Tantry US, Gurbel PA. Cigarette smoking and clopidogrel interaction. Curr Cardiol Rep 2013;15:361.

2. Gagne JJ, Bykov K, Choudhry NK, Toomey TJ, Connolly JG, Avorn J. Effect of smoking on comparative efficacy of antiplatelet agents: systematic review, metaanalysis, and indirect comparison. BMJ 2013;347:f5307.
The Editorial Executive Committee welcomes letters, which should be less than 250 words. Before a decision to publish is made, letters which refer to a published article may be sent to the author for a response. Any letter may be sent to an expert for comment. When letters are published, they are usually accompanied in the same issue by any responses or comments. The Committee screens out discourteous, inaccurate or libellous statements. The letters are sub-edited before publication. Authors are required to declare any conflicts of interest. The Committee's decision on publication is final. 